\section{BMJ Paediatrics Open}

\title{
Intubating extremely premature newborns: a randomised crossover simulation study
}

Joseph O'Connell, Gary Weiner

To cite: 0 'Connell J, Weiner G. Intubating extremely premature newborns: a randomised crossover simulation study. BMJ Paediatrics Open 2017;1:e000157. doi:10.1136/ bmjpo-2017-000157

Received 13 June 2017 Revised 11 August 2017 Accepted 14 August 2017

\section{CrossMark}

Division of Neonatal-Perinatal Medicine, Department of Pediatrics and Communicable Diseases, University of Michigan, Ann Arbor, Michigan, USA

\section{Correspondence to}

Dr Gary Weiner; gweiner@med. umich.edu

\section{ABSTRACT}

Objective Determine whether tracheal intubation of extremely low birthweight (ELBW) neonates is more successful with a size-0 or size-00 Miller laryngoscope blade.

Design Randomised crossover simulation study Setting Simulated neonatal intensive care unit environment

Study subjects Neonatology physicians and nurse practitioners $(n=55)$

Interventions Subjects performed four intubations in succession on a high-fidelity ELBW manikin with size0 Miller and size-00 Miller blades from two different manufacturers. The intubation sequence was randomised. Intubations were recorded and scored for time analysis. Subjects completed surveys about blade preferences before and after completing the series of intubations.

Main outcome measures Total laryngoscopy time and first attempt success in less than $30 \mathrm{~s}$

Results There was no difference in total laryngoscopy time (median 23.7 vs $20.6 \mathrm{~s}$ ) or first attempt success in $<30$ s ( $67.3 \%$ vs $69.1 \%$ ) between the size- 0 and size-00 blades. Differences were noted between the same size blades made by different manufacturers. Among subjects expressing a prestudy blade size preference, there was no difference in laryngoscopy time or first attempt success between blades. Regardless of blade size, subjects were less successful with the first blade in the randomised sequence.

Conclusions Our findings support the Neonatal Resuscitation Program recommendation identifying the size-00 blade as optional equipment. Operators need to be aware of design variations between manufacturers and they may benefit from 'just-in-time' training with a manikin prior to intubating a live patient.

\section{INTRODUCTION}

Direct laryngoscopy for tracheal intubation is an important but challenging skill for healthcare providers. Despite an increased emphasis on non-invasive ventilation, more than half of preterm infants <28 weeks' gestation will require tracheal intubation for surfactant administration or mechanical ventilation. ${ }^{1}$ Several studies have demonstrated that providers have relatively low proficiency with neonatal tracheal intubation. ${ }^{2-5}$ As a result,

\section{What is already known on this topic?}

- Preterm infants <28 weeks' gestation frequently require tracheal intubation, and frequently undergo multiple unsuccessful intubation attempts.

- The Neonatal Resuscitation Program recommends the size-0 Miller laryngoscope blade for premature neonates and describes the size-00 Miller blade as optional.

- The actual dimensions of size- 0 and size-00 laryngoscopes vary among different manufacturers.

\section{What this study adds?}

- There are no significant differences in performance characteristics between the size- 0 and size- 00 Miller laryngoscope blades when intubating a highfidelity extremely low birthweight manikin.

- Design variations between manufacturers may affect performance.

- Neonatal providers may benefit from 'just-in-time' training with a simulated intubation just prior to intubating a real patient.

newborns frequently undergo multiple unsuccessful intubation attempts which increase the risk of adverse outcomes. ${ }^{2} 467$ Operator-related factors such as experience, choice of preprocedure medications and device selection affect the likelihood of first attempt success. ${ }^{89}$ The American Academy of Pediatrics' Neonatal Resuscitation Program (NRP) textbook includes the size-0 Miller laryngoscope blade in the list of standard supplies recommended for every delivery room. ${ }^{10}$ The size-00 Miller blade is described as an optional device that may be preferred for very preterm infants. Other textbooks recommend the size- 00 Miller blade for all infants $<27$ weeks' gestation or weighing $<750$ g. ${ }^{11}$ This shorter blade may be easier to insert into the very preterm newborn's mouth; however, once the blade is inserted the shorter length may offer less control of the baby's tongue and the blade's heel may press 
against the baby's mouth. Moreover, the actual dimensions of size- 0 and size-00 blades vary between manufacturers. ${ }^{12}$ Currently, individual operator preference drives device selection and no studies have compared success with these two laryngoscope blades. Identifying the ideal blade size may decrease laryngoscopy time, improve first attempt intubation success and reduce adverse events. Our aim was to determine whether operators intubating a high-fidelity manikin simulating an extremely low birthweight (ELBW) newborn (population) with a size-00 Miller blade (intervention) compared with a size-0 Miller blade (comparison) would require less total laryngoscopy time (primary outcome) and have greater first attempt success within $30 \mathrm{~s}$ (secondary outcome).

\section{METHODS}

Volunteer neonatal intensive care unit (NICU) providers including neonatologists, fellows and neonatal nurse practitioners were recruited from four tertiary perinatal medical centres (University of Michigan C.S. Mott Children's Hospital, Ann Arbor, Michigan, USA; Advocate Children's Hospital, Oak Lawn, Illinois, USA; St. John Providence Hospital, Detroit, Michigan, USA; St. Joseph Mercy Hospital, Ann Arbor, Michigan, USA) for this randomised crossover simulation study.

Using a prestudy survey, participants indicated their professional role, years of clinical neonatology experience, self-perceived confidence in laryngoscopy skill (5-point rating scale) and preferred laryngoscope blade size for intubating an extremely preterm newborn. Using four different laryngoscope blades, participants orally intubated a high-fidelity neonatal manikin that simulated a 25-week gestation newborn (Premature Anne, Laerdal Medical, Wappingers Falls, New York, USA). The study blades included one size- 0 Miller and one size-00 Miller blade made by two different manufacturers (Welch-Allyn (WA), Skaneateles Fall, New York, USA and Rusch-Teleflex (RT), Morrisville, North Carolina, USA) (figure 1). The blades were selected to reflect those used in routine clinical practice at participating centres. The sequence that each blade was presented was randomly allocated using a computer-generated table (http://www. graphpad.com/quickcalcs/randomize1.cfm) and assignments were concealed in opaque sealed envelopes. Each intubation was performed using an uncuffed $2.5 \mathrm{~mm}$ internal diameter tracheal tube (Mallinckrodt, Mallinckrodt Pharmaceuticals, St. Louis, Missouri, USA) and an optional intubating stylet (Sheri-I-Slip, Hudson RCI/ Teleflex, Morrisville, North Carolina, USA). Participants assembled their equipment and positioned the manikin on an adjustable radiant warmer as they would for a typical neonatal intubation. To ensure standardisation and avoid bias, participants were not allowed to practice intubation with the study blades; however, they were shown a photograph of the manikin's airway and vocal cords for orientation purposes. One investigator handed the participant each blade in the assigned order and was available to provide cricoid pressure if requested. Using each of the four blades, participants were allowed as many attempts and as much time as required to successfully intubate the manikin. An attempt was defined as insertion of the blade into the manikin's mouth, regardless of whether the tracheal tube was inserted. ${ }^{5}$ The duration of an intubation attempt was defined as the interval from insertion of the blade into the manikin's mouth until it was fully removed. All attempts using a single blade are referred to as a blade trial. A digital video camera (Logitech HD Pro C920, Logitech, Newark, California, USA) was used to record each intubation attempt for subsequent time analysis by an investigator who was masked to the blade sequence. The laryngoscopy time for each attempt was recorded. If more than one attempt was required, the data for each attempt were summed to calculate the total laryngoscopy time for each blade trial. Successful intubation was indicated by chest movement during positive-pressure ventilation as assessed by the on-site investigator. After each successful intubation, the participant was offered a rest period and asked to reset the intubating environment before the next blade trial. On completing all four blade trials, participants completed a poststudy survey that asked which single blade was most preferred and which was least preferred. Using a 5-point rating scale, participants were asked how accurately the manikin represented a premature newborn's airway.

We hypothesised that intubation using the size- 00 blade compared with the size- 0 blade would decrease the total laryngoscopy time. Secondary outcome measures included the proportion of trials with first attempt success in $<30 \mathrm{~s}$ and the total number of attempts required to successfully intubate the manikin. Planned subanalyses included laryngoscopy time and success rate stratified by trial number and by the operator's prestudy blade preference. For the primary analysis (size-0 vs size-00), total laryngoscopy time for each participant using the two blades of the same size were averaged. In secondary analyses, results for each of the four blades were analysed individually. The baseline laryngoscopy time and distribution were estimated from the study by Bismilla $e t$ al describing neonatal intubations at a high-risk perinatal centre. ${ }^{4} \mathrm{We}$ defined a clinically significant difference as the interval between this baseline (50s) and the current NRP intubation time standard $(30 \mathrm{~s}) .{ }^{10}$ We estimated a sample size of 48 participants would be required to find this 20 s difference in mean laryngoscopy time when evaluating each of the four blades separately $(\mathrm{m} 1=50 \mathrm{~s}, \mathrm{~m} 2=30 \mathrm{~s}, \mathrm{SD}=28 \mathrm{~s}$, four groups with six pairwise comparisons, alpha 0.05 , power 0.80$).{ }^{413}$

Continuous variables are reported as medians and IQRs. Group comparisons for independent continuous variable were conducted using the Kruskal-Wallis test. Paired continuous variables were compared using the Wilcoxon matched-pairs signed rank test or Friedman's test with Dunn's multiple comparisons post-test. Categorical variables are reported as counts with percentages and outcomes were compared with the $\mathrm{X}^{2}$ test or McNemar's 


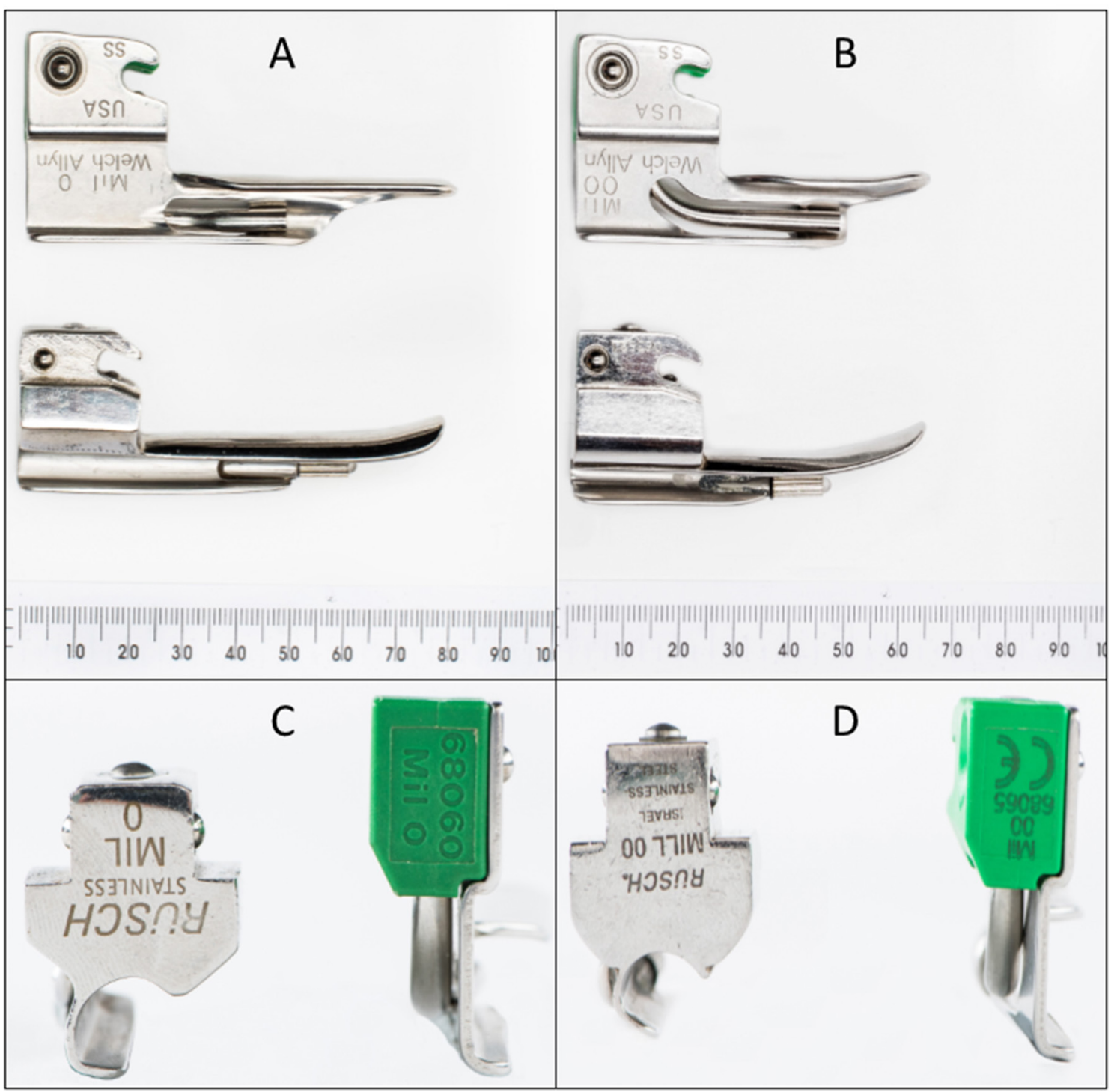

Figure 1 Study laryngoscope blades. (A) Size-0 Miller Welch-Allyn (top) and size-0 Miller Rusch-Teleflex (bottom). (B) Size-00 Miller Welch-Allyn (top) and size-00 Miller Rusch-Teleflex (bottom). (C) Size-0 Miller Welch-Allyn (right) and size-0 Miller RuschTeleflex (left). (D) Size-00 Miller Welch-Allyn (right) and size-00 Miller Rusch-Teleflex (left).

test for matched-pairs with continuity correction. All analyses were two-tailed and a $p$ value $<0.05$ was considered to be statistically significant. Statistical analyses were conducted using Prism V.6.01 (GraphPad Software, La Jolla, California, USA).

The study was reviewed and assigned exempt status by the University of Michigan Institutional Review Board. Written consent was obtained from all study participants.

\section{RESULTS}

Fifty-five NICU providers with a median of 10.5 years of clinical NICU experience participated in the study (table 1). Participants were confident in their laryngoscopy skill and $56 \%$ indicated a prestudy preference for the size-00 Miller blade. When combining results for the WA and RT blades, there was no significant difference in laryngoscopy time between the size- 0 and size-00 blades for the entire group or after stratification by prestudy blade preference (table 2 ). When considering each of the four blades individually, the total laryngoscopy time was very similar. The only significant difference in laryngoscopy time was between the WA size- 0 blade and the RT size- 0 blade $(22.3 \mathrm{~s}$ vs $19.1 \mathrm{~s}$, $\mathrm{p}=0.02)$. Post hoc two-way repeated measures analysis of variance confirmed no main effect of blade size or manufacturer but a significant interaction between blade size and manufacturer $(p=0.006)$ indicating that design variations between the manufacturers had different effects on laryngoscopy time depending on the blade size. Regardless of the blade used, laryngoscopy time was significantly longer for the first blade trial compared with all other trials. The median difference in laryngoscopy time between the first and last blade trial was $11.6 \mathrm{~s}$ (table 2). 


\begin{tabular}{lr}
\hline \multicolumn{2}{l}{ Table $1 \quad$ Characteristics of study participants $(n=55)$} \\
\hline \multicolumn{2}{l}{ Variable } \\
\hline Role, $\boldsymbol{n}(\%)$ & $21(38.2)$ \\
\hline Neonatologist & $8(14.5)$ \\
\hline Neonatology fellow & $26(47.2)$ \\
\hline Neonatal nurse practitioner & $10.5(3,20)$ \\
\hline Neonatology experience, years, median (IQR) & $4(4,5)$ \\
Confidence level ${ }^{*}$, median (IQR) & \\
\hline Laryngoscope blade preference, $n(\%)$ & $17(30.9)$ \\
\hline Size-0 & $31(56.3)$ \\
\hline Size-00 & $7(12.7)$ \\
\hline
\end{tabular}

*Self-reported 5-point rating scale (1=least confident, $5=$ most confident).

When combining results for the WA and RT blades, there was no significant difference in the median number of attempts ( 1 vs $1, p=0.43$ ) or the proportion of trials with first attempt success within 30 s $(74 \%$ vs $76 \%, \mathrm{p}=0.68$ ) (table 3 ). When each blade was considered individually, participants were least successful using the

\begin{tabular}{|c|c|c|}
\hline $\begin{array}{l}\text { Time by blade size } \\
\text { (manufacturers combined) }\end{array}$ & $\begin{array}{l}\text { Seconds } \\
\text { Median (IQR) }\end{array}$ & p Value \\
\hline \multicolumn{3}{|l|}{ All participants $(n=55)$} \\
\hline Size-0 & $23.7(15.4,46.7)$ & 0.92 \\
\hline Size-00 & $20.6(16.0,36.0)$ & \\
\hline \multicolumn{3}{|l|}{$\begin{array}{l}\text { Participants preferring size- } 0 \\
(n=17)\end{array}$} \\
\hline Size-0 & $28.3(16.7,46.4)$ & 0.89 \\
\hline Size-00 & $21.0(16.3,45.0)$ & \\
\hline \multicolumn{3}{|l|}{$\begin{array}{l}\text { Participants preferring size- } \\
00(n=31)\end{array}$} \\
\hline Size-0 & $23.4(14.3,46.7)$ & 0.95 \\
\hline Size-00 & $20.6(16.1,46.4)$ & \\
\hline \multicolumn{3}{|l|}{$\begin{array}{l}\text { Time by blade size } \\
\text { (individual blades) }\end{array}$} \\
\hline Size-0 (WA) & $22.3(16.4,26.9)$ & $0.02^{*}$ \\
\hline Size-0 (RT) & $19.1(12.1,26.9)$ & \\
\hline Size-00 (WA) & $18.9(12.5,31.8)$ & \\
\hline Size-00 (RT) & $18.1(12.9,31.5)$ & \\
\hline \multicolumn{3}{|l|}{ Time by trial number } \\
\hline First blade trial & $26.9(19.5,62.9)$ & $<0.001 \dagger$ \\
\hline Second blade trial & $18.6(14.6,30.3)$ & \\
\hline Third blade trial & $17.8(13.2,28.1)$ & \\
\hline Fourth blade trial & $15.3(10.9,28.7)$ & \\
\hline
\end{tabular}

*Size-0 (WA) vs all other blades.

†First blade trial vs all other blade trials.

RT, Rusch-Teleflex; WA, Welch-Allyn.
Table 3 First attempt success in $<30 \mathrm{~s}$

\begin{tabular}{lll}
\hline Success by blade size & N (\%) & p Value \\
\hline $\begin{array}{l}\text { Manufacturers combined } \\
\text { Size-0 (combined) }\end{array}$ & $74(67.3)$ & 0.68 \\
\hline $\begin{array}{l}\text { Size-00 (combined) } \\
\text { Individual blades }\end{array}$ & $76(69.1)$ & \\
\hline Size-0 (WA) & $30(54.5)$ & 0.04 \\
\hline Size-0 (RT) & $44(80.0)$ & \\
\hline Size-00 (WA) & $38(69.1)$ & \\
\hline Size-00 (RT) & $38(69.1)$ & \\
& OR (95\% Cl) & p Value \\
\hline Size-0 (RT) vs size-0 (WA) & $2.71(1.09$ to 7.64$)$ & 0.03 \\
\hline Size-00 (RT) vs size-0 (RT) & $0.36(0.08$ to 1.23) & 0.12 \\
\hline Size-00 (WA) vs size-0 (WA) & $2.33(0.84$ to 7.41$)$ & 0.12 \\
\hline Size-00 (RT) vs size-00 (WA) & $1.00(0.35$ to 2.84) & 0.81 \\
\hline Success by trial number & $\mathrm{N}(\%)$ & $\mathrm{p} \mathrm{Value}$ \\
\hline First blade trial & $28(50.9)$ & $0.02^{*}$ \\
\hline Second blade trial & $41(74.5)$ & \\
\hline Third blade trial & $40(72.7)$ & \\
\hline Fourth blade trial & $41(74.5)$ & \\
\hline
\end{tabular}

${ }^{*}$ First blade trial vs all other blade trials.

RT, Rusch-Teleflex; WA, Welch-Allyn.

WA size- 0 blade and most successful with the RT size- 0 blade $(\mathrm{p}=0.04)$. In pairwise matched comparisons, this was the only statistically significant difference. Similar to the finding for laryngoscopy time, regardless of the blade size or manufacturer, participants were significantly less successful with the first blade trial compared with subsequent trials.

On the poststudy survey, operator preference was evenly distributed between the size- 0 and size- 00 blades (21 participants each). The most preferred individual blades were the RT size- 0 and the WA size- 00 blades (12 participants each). Using a 5-point rating scale (1=strongly disagree, $5=$ strongly agree), participants indicated that the study manikin accurately represented a live newborn airway (mean 3.9, SD 0.84; median 4, IQR 4, 4).

\section{DISCUSSION}

In this randomised crossover study, we investigated whether experienced providers were more successful intubating a manikin simulating a 25-week gestation newborn using a size-0 Miller or a size-00 Miller laryngoscope blade. Participants used blades produced by two different manufacturers. In the primary analysis, we found no significant difference in total laryngoscopy time or first attempt success $<30$ s between the size- 0 and size-00 blades. Although most participants expressed a prestudy preference for a particular size, we found no significant difference in outcome measures when results were stratified by blade preference. On the poststudy 
survey, many participants changed their initial preference to the opposite size blade. Ultimately, the two most preferred blades included one of each size. Given the wider range of patients that can be intubated using a size- 0 blade and the similarity in performance characteristics, our findings support the NRP textbook recommendation describing the size-00 blade as optional equipment based on operator preference. ${ }^{10}$

In secondary analyses, we found significant differences in outcome measures when comparing the same size blade made by two different manufacturers. Participants took longer to intubate and were less successful using the WA size- 0 blade compared with the RT size- 0 blade. Both blades are described as a Miller size- 0 ; however, the WA blade is slightly shorter and flatter than the RT blade and the viewing channel has a taller and narrower profile (figure 1). Although the WA size-00 blade has the same design variations, it performed as well as the RT size-00 blade and was rated by participants as one of the most preferred blades. We hypothesise that the narrow shape of the viewing channel caused more difficulty with the WA size-0 blade because a longer portion of the narrow channel remained outside of the manikin's mouth causing more difficulty with laryngeal view and tube insertion. Intermanufacturer variations in the design and dimensions of laryngoscope blades have been previously described. ${ }^{12}$ The significant interaction between manufacturer and blade size suggests that intermanufacturer design variation may impact performance differently based on the blade size and should be considered when selecting devices.

The sequence of attempts accounted for the greatest difference in both laryngoscopy time and first attempt success. Regardless of the blade used, operators required more time and were less successful during the first blade trial compared with all other trials. The absolute difference in first attempt success was nearly $24 \%$ between the first and second blade trial. The difference may indicate that operators were unfamiliar with the manikin and needed practice to become comfortable with the simulated airway. Given the difficulty in standardising practice, we decided not to allow prestudy practice to ensure that all participants began the study with the same initial experience. Because the blade sequence was randomised, the confounding effect of trial order was evenly distributed between the four different blades. In a broader sense, our findings suggest that operators may benefit from 'justin-time' training by performing a simulated intubation immediately before intubating a live patient. ${ }^{14}$ Although simulation education did not improve clinical success with neonatal intubation in a small study using historical controls, the simulation activity was separated by up to 8 weeks from the clinical intubation. ${ }^{15}$ A randomised controlled trial evaluating a 'just-in-time' simulation with a high-fidelity manikin is indicated.

The primary limitation of this study is that it was performed using a manikin. A simulation setting was chosen because of the practical difficulties anticipated in enrolling a sufficient number of ELBW newborns to compare intubations using four devices while controlling for different levels of neonatal provider experience. In the simulation environment, participants were able to use each of the blades and serve as their own control. It is not clear, however, that intubation performance measured with a manikin accurately reflects real-life performance and caution must be interpreted when interpreting these results. Differences in the conditions created during simulation, including the operator's stress level, the manikin's anatomy and the absence of spontaneous movement and oral secretions in the manikin may limit the ability to translate these results to clinical practice. ${ }^{16}$ Technical skills acquired in a variety of simulation-based training programme have been shown to transfer to the clinical environment. ${ }^{17-22}$ More specifically, airway management skills acquired in simulation tend to correlate with improved behavioural skills, technical skills and proficiency suggesting some translation between simulation and clinical practice. ${ }^{23-25}$ In a study of paramedic students learning intubation, the clinical success rate was nearly identical $(87.8 \%$ vs $84.8 \%)$ between those trained with a simulator and those trained with human subjects in the operating room. ${ }^{26}$ In the present study, participants served as their own controls minimising the effect of operator stress and the lack of patient movement or secretions. Ensuring accurate representation of the newborn airway is likely the most relevant issue regarding translation of our study results. Lack of anatomic fidelity has been described in several previous human simulators. ${ }^{27} 28$ Although manikin may not perfectly replicate the experience of intubating a live newborn, the manikin used for this study has been previously evaluated and found to have high anatomic and functional fidelity. ${ }^{29}$ Participants in our study verified these findings on the poststudy survey. Still, replicating these findings in a human study that includes smaller preterm newborns would strengthen the conclusion of equivalency between the size- 0 and size- 00 blades .

Operators in our study required less baseline laryngoscopy time than anticipated. This may reflect that our participants had more experience than those described by Bismilla et al. ${ }^{4}$ Although this decreased the statistical power, we do not feel that the small differences demonstrated in either laryngoscopy time or first attempt success would be considered clinically relevant if there had been sufficient power to find a statistically significant difference. Given the similar performance between blades, our data suggest that a randomised trial in extremely premature newborns would require a large sample size to find a statistically significant difference in either laryngoscopy time or first attempt success.

\section{CONCLUSION}

Combining the results between two manufacturers, we found no significant difference in laryngoscopy time or first attempt success within $30 \mathrm{~s}$ between size- 0 and size- 00 
Miller laryngoscopy blades. When analysing each blade individually, significant differences in performance were possibly related to design variations between manufacturers. Our findings support the NRP textbook recommendation that the size- 0 Miller blade should be considered standard equipment and the size-00 Miller blade should be considered optional equipment. The most significant difference was related to the order that blades were presented, which suggests that 'just-in-time' training with a simulated intubation performed immediately before a clinical intubation may improve performance.

Contributors $\mathrm{JO}^{\prime} \mathrm{C}$ and GW both significantly contributed to formulating the study question, the study design, recruiting study participants, statistical analysis and manuscript preparation. J0' $\mathrm{C}$ was the on-site investigator and GW performed the masked time analysis using the video-recorded material.

Competing interests None declared.

Ethics approval University of MIchigan Institutional Review Board.

Provenance and peer review Not commissioned; externally peer reviewed.

Data sharing statement There are no additional unpublished data. Video recordings of study subjects have been deleted, as indicated in the study consent. Survey data and data scored from the video recordings remain available only to JO'C and GW.

Open Access This is an Open Access article distributed in accordance with the Creative Commons Attribution Non Commercial (CC BY-NC 4.0) license, which permits others to distribute, remix, adapt, build upon this work non-commercially, and license their derivative works on different terms, provided the original work is properly cited and the use is non-commercial. See: http://creativecommons.org/ licenses/by-nc/4.0/

(c) Article author(s) (or their employer(s) unless otherwise stated in the text of the article) 2017. All rights reserved. No commercial use is permitted unless otherwise expressly granted.

\section{REFERENCES}

1. Finer NN, Carlo WA, Walsh MC, et al. Early CPAP versus surfactant in extremely preterm infants. N Engl J Med 2010;362:1970-9.

2. O'Donnell CP, Kamlin CO, Davis PG, et al. Endotracheal intubation attempts during neonatal resuscitation: success rates, duration, and adverse effects. Pediatrics 2006;117:e16-e21.

3. Leone TA, Rich W, Finer NN. Neonatal intubation: success of pediatric trainees. J Pediatr 2005;146:638-41.

4. Bismilla Z, Finan E, McNamara PJ, et al. Failure of pediatric and neonatal trainees to meet Canadian Neonatal Resuscitation Program standards for neonatal intubation. J Perinatol 2010;30:182-7.

5. Lane B, Finer N, Rich W. Duration of intubation attempts during neonatal resuscitation. J Pediatr 2004;145:67-70.

6. Wallenstein MB, Birnie KL, Arain YH, et al. Failed endotracheal intubation and adverse outcomes among extremely low birth weight infants. J Perinatol 2016;36:112-5.

7. Wozniak M, Arnell K, Brown M, et al. The 30 second rule: the effects of prolonged intubation attempts on oxygen saturation and heart rate in preterm infants in the delivery room. Minerva Pediatr 2016.

8. Natt BS, Malo J, Hypes CD, et al. Strategies to improve first attempt success at intubation in critically ill patients. $\mathrm{Br} J$ Anaesth 2016;117:i60-i68.
9. Foglia EE, Ades A, Napolitano N, et al. Factors Associated with Adverse Events during Tracheal Intubation in the NICU. Neonatology 2015;108:23-9.

10. Weiner GM, Zaichkin J, Kattwinkel J. American academy of pediatrics, association AH. Textbook of neonatal resuscitation. 7th edition. Elk Grove Village IL: American Academy of Pediatrics, 2016:313.

11. Wyckoff $\mathrm{MH}$. Respiratory and cardiovascular support in the delivery room. In: Bancalari E, Polin RA, eds. The newborn lung: neonatology questions and controversies. 2nd ed. Philadelphia: Elsevier/ Saunders, 2012.

12. Kieran EA, O' Donnell CP, Od CP. Variation in size of laryngoscope blades used in preterm newborns. Arch Dis Child Fetal Neonatal Ed 2014;99:F250.

13. Chow S-C, Wang H, Shao J. Sample size calculations in clinical research. 2nd ed. Boca Raton: FL: Chapman and Hall/CRC, 2007.

14. Braga MS, Tyler MD, Rhoads JM, et al. Effect of just-in-time simulation training on provider performance and patient outcomes for clinical procedures: a systematic review. BMJ Simulation and Technology Enhanced Learning 2015;1:94-102.

15. Finan E, Bismilla Z, Campbell C, et al. Improved procedural performance following a simulation training session may not be transferable to the clinical environment. J Perinatol 2012;32:539-44.

16. Rai MR, Popat MT. Evaluation of airway equipment: man or manikin? Anaesthesia 2011;66:1-3.

17. Grantcharov TP, Kristiansen VB, Bendix J, et al. Randomized clinical trial of virtual reality simulation for laparoscopic skills training. $\mathrm{Br} \mathrm{J}$ Surg 2004;91:146-50.

18. Barsuk JH, Cohen ER, Caprio T, et al. Simulation-based education with mastery learning improves residents' lumbar puncture skills. Neurology 2012;79:132-7.

19. Barsuk JH, Cohen ER, Mikolajczak A, et al. Simulation-based mastery learning improves central line maintenance skills of ICU nurses. J Nurs Adm 2015;45:511-7.

20. Barsuk JH, Cohen ER, Vozenilek JA, et al. Simulation-based education with mastery learning improves paracentesis skills. J Grad Med Educ 2012;4:23-7.

21. McGaghie WC, Issenberg SB, Barsuk JH, et al. A critical review of simulation-based mastery learning with translational outcomes. Med Educ 2014;48:375-85.

22. Griswold-Theodorson S, Ponnuru S, Dong C, et al. Beyond the simulation laboratory: a realist synthesis review of clinical outcomes of simulation-based mastery learning. Acad Med 2015;90:1553-60.

23. Kennedy CC, Cannon EK, Warner DO, et al. Advanced airway management simulation training in medical education: a systematic review and meta-analysis. Crit Care Med 2014;42:169-78.

24. Mills DM, Williams DC, Dobson JV. Simulation training as a mechanism for procedural and resuscitation education for pediatric residents: a systematic review. Hosp Pediatr 2013;3:167-76.

25. Mills DM, Wu CL, Williams DC, et al. High-fidelity simulation enhances pediatric residents' retention, knowledge, procedural proficiency, group resuscitation performance, and experience in pediatric resuscitation. Hosp Pediatr 2013;3:266-75.

26. Hall RE, Plant JR, Bands CJ, et al. Human patient simulation is effective for teaching paramedic students endotracheal intubation. Acad Emerg Med 2005;12:850-5.

27. Schebesta K, Hüpfl M, Rössler B, et al. Degrees of reality: airway anatomy of high-fidelity human patient simulators and airway trainers. Anesthesiology 2012;116:1204-9.

28. Schebesta K, Hüpfl M, Ringl H, et al. A comparison of paediatric airway anatomy with the SimBaby high-fidelity patient simulator. Resuscitation 2011;82:468-72.

29. Sawyer T, Strandjord TP, Johnson K, et al. Neonatal airway simulators, how good are they? A comparative study of physical and functional fidelity. J Perinatol 2016;36:151-6. 